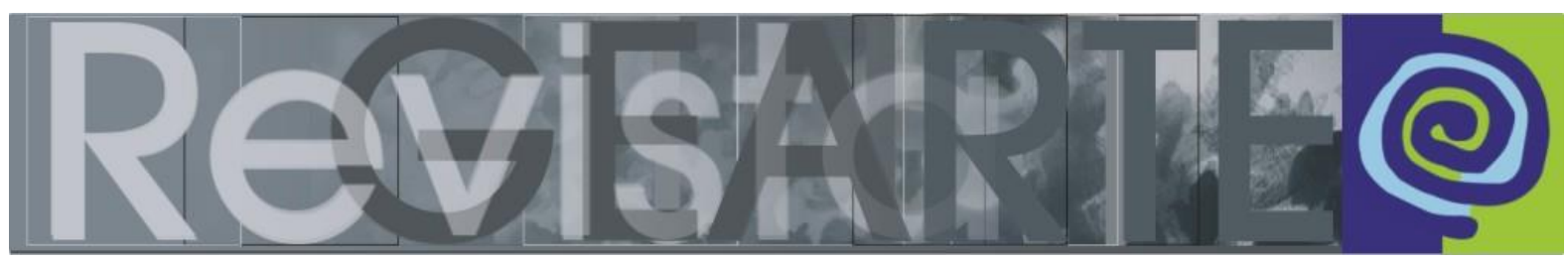

e-ISSN 2357-9854

\title{
Abordagem Triangular
}

Ensaio poético

Regina Machado (Universidade de São Paulo — USP, São Paulo/SP, Brasil)

"Luz do sol

Que a folha traga e traduz

Em verde novo,

em folha, em graça,

Em vida, em força, em luz."

Caetano Veloso

O que me proponho a fazer nesse texto é um exercício de liberdade. Desde o primeiro momento em que entrei em contato com a formulação inicial da Abordagem Triangular para o ensino e aprendizagem da arte formulada por Ana Mae Barbosa, é isso que tenho buscado fazer, inspirada por tudo que aprendi e continuo aprendendo com ela: instigada pela curiosidade investigativa inquebrantável que a anima ainda hoje, e que, entre outras qualidades, é responsável pela pessoa em que ela foi se transformando ao longo do tempo. Ana Mae se tornou a mais importante, a mais fecunda fonte de conhecimento a serviço do ensino e aprendizagem da Arte no Brasil. Seu trabalho é singular, paradigmático e livre, tendo seu lugar assegurado, como nenhum outro, na História dessa área de reflexão e prática educativa. Mesmo que muito tempo ainda tenha que se desenrolar para que esse lugar seja compreendido e justamente valorizado, como é comum a muitas propostas visionárias.

\section{Quem viver, verá, diz o dito popular}

Isso não é um elogio à toa. Pretendo, se me for possível, compartilhar uma compreensão particular, que chamo de teórico poética, no convívio com a Abordagem Triangular. Feita de memórias, afetos, pensamentos, intuições, muitas perguntas e riscos. Não poderia ser menos do que isso para fazer jus à apaixonada entrega com que Ana Mae dedicou sua vida a serviço do poder transformador da Arte na vida do ser humano. 
Quero olhar para a Abordagem Triangular à luz dos três eixos que a compõem: em cada vértice do triângulo um conjunto de ações que circunscrevem modos diversos e complementares de aproximação da arte em suas múltiplas possibilidades de conhecimento. Contextos, leituras e produção de formas artísticas: o triângulo estabelece inicialmente distinções e ao mesmo tempo inúmeras relações em diferentes dimensões e sentidos entre esses diversos eixos de ações. Distinguir e relacionar como um começo frutífero para a compreensão de que cada eixo tem características próprias, mas só existe na complementaridade que se configura na experiência de aprendizagem de cada sujeito situado precisamente no ponto central de cada triângulo.

Quais são os possíveis contextos dessa Abordagem?

Que leituras nos convida a fazer?

Que tipo de produção realiza na área de Ensino e aprendizagem da Arte?

\section{Os contextos da AbordagemTriangular}

Final do século XX. Após um certo tempo de vigorosa mudança paradigmática e conquistas importantes inauguradas no começo do século por uma saudável revolução chamada de Modernista, manifesta em diversos campos do conhecimento, as palavras de ordem da Livre Expressão e do "aprender fazendo" chegaram a um declínio sintomático. Era preciso ir além e questionar as práticas educativas no campo da arte, reduzidas ao longo do tempo a um esvaziamento mecânico, exaurido dos ideais tão belamente sonhados por inúmeros investigadores.

John Dewey - principalmente - no início do século XX e Viktor Lowenfeld com suas descobertas sinalizadoras de caminhos para muitas gerações de arte educadores - , foram deixados para trás. Muitas vezes até hoje mal compreendidos, esses e outros autores viraram passado, quando a era da pós-modernidade se instalou, advogando novos paradigmas para um novo tempo. 
Sem dúvida surgiram perguntas fundamentais, afinal, dizia-se - será que as práticas educativas da Livre Expressão poderiam dar conta de experiências significativas de aprendizagem no contato com a Arte?

Essa e outras perguntas em grande rebuliço engrossaram a onda gigantesca que se levantou nas últimas décadas do século XX entre arte educadores, sacudindo o marasmo enfadonho dos restos mortais do Modernismo e abrindo novas e fecundas frentes de reflexão e ação críticas.

Um problema comum aos movimentos históricos em geral pode ser vulgarmente conhecido como o ato de "jogar o bebê fora junto com a água da bacia": tudo que se aprendeu, mal ou bem com as propostas modernistas, tinha que ser substituído e deixado de lado.

Ana Mae formou-se dentro do Modernismo e nunca deixou de questionar e investigar seus pressupostos, guiada pela pesquisa incansável de tudo que podia ler, estudar, visitar, escrever e realizar concretamente em nosso país e em outros lugares por onde andou.

Seu olhar para a História do Ensino da Arte, em seus meandros e implicações de todos os tipos, assegurou-Ihe o exercício cumulativo de um pertencimento à cultura brasileira em constante diálogo com a produção de outros países. Assim seu olhar foi aos poucos se formando na dupla articulação entre, de um lado, o reconhecimento e estudo de raízes brasileiras do pensamento relacionado à educação e ao ensino da Arte e, de outro, a observação atenta e crítica dos movimentos contemporâneos e iniciativas forjadas em outros lugares do mundo.

O fio condutor da investigação histórica foi postulado por ela num posicionamento arguto, consciente das contribuições frutíferas do passado em conversa com as realidades do presente. Esse fio condutor foi em grande medida responsável pela sua síntese visionária da Proposta Triangular. Sem nunca jogar fora o bebê com a água da bacia, pode amalgamar ensinamentos de seus mestres (Paulo Freire e Noemia Varela liderando uma lista grande de pensadores brasileiros, por exemplo) com seus questionamentos e aprendizagens junto às experiências pós- 
modernas mundo afora, transfigurando-os à luz de seu conhecimento da História do ensino da Arte, contexto maior que fundamenta seu agir e pensar.

Numa formulação simples e ao mesmo tempo extremamente complexa, a Abordagem Triangular é uma criação particular, ao estabelecer que não se aprende arte apenas fazendo, mas que a produção artística significativa de aprendizes depende de um exercício crítico e estético no contato com obras de arte produzidas ao longo da História da humanidade, cuja compreensão depende por sua vez dos contextos significativos em que foram criadas. Então a experiência de aprender Arte se faz na confluência desses três eixos de aproximação e ação investigativa.

\section{Como?}

A meu ver, a principal contribuição da Abordagem de Ana Mae é justamente não criar uma metodologia, como fizeram outros tantos arte educadores.

Ninguém pode ensinar "como" a ninguém. Um arte educador precisa de uma formulação sólida de princípios para guiar seu próprio caminho metodológico. Uma estrutura que delimite os contornos de sua área de conhecimento. Que abra possibilidades de ação a partir da compreensão da natureza de seu objeto de estudo em suas múltiplas relações em diversos níveis de realidade. Precisamente o que propicia a Abordagem Triangular.

\footnotetext{
Enquanto estrutura de possibilidades, caracteriza o fenômeno da Arte como objeto de conhecimento na sua especificidade, distinguindo-o de outros objetos de conhecimento. Imagino que desde o início da humanidade, mesmo exercendo as mais diferentes funções dentro do conjunto de cada cultura humana, o fenômeno que hoje chamamos Arte sempre foi aprendido, ensinado e transmitido por meio da produção de formas, da leitura dessas formas e do pensamento que as contextualiza, relacionando-as entre si (MACHADO, 2010, p. 68).
}

Lembro sempre de meu pai citando um autor — desse, infelizmente, não me lembro o nome... - que dizia que nada é novo, mas "o arranjo dos dados conhecidos, sim, esse é novo".

Na História do ensino da Arte no Brasil o "arranjo" da Abordagem Triangular é completamente novo e original: "[...] delimita os contornos do conhecimento artístico, 
estruturando um campo de ações que conduzem processos de aprendizagem, específicos dessa forma de conhecimento humano" (MACHADO, 2010, p. 72).

Numa reunião de professores em uma escola, o arte educador não precisa mais dizer, por exemplo, que o objetivo de seu trabalho com os alunos é "desenvolver a criatividade". A partir de sua compreensão da Abordagem Triangular poderá formular respostas mais precisas e fundamentadas a seus colegas. E em muitas outras situações, como preparar suas aulas e assim por diante.

\section{Leituras}

Fui aos poucos percebendo que a Abordagem Triangular contém variados triângulos, tantos quantos forem as situações de aprendizagem criadas ao longo de uma prática educativa

O educador, os alunos e o ensino da Arte. Aquele educador, aqueles alunos e aquela aula. Os alunos, a escola e a intenção do educador. A Arte, o mundo e a produção escolar. O artista, sua vida e sua obra. A cultura popular, as vanguardas contemporâneas e os conceitos de Arte. A Arte, a Natureza e a Cultura. E assim interminavelmente. Tal multiplicidade e multiplicação de triângulos é fruto de uma estrutura flexível, aberta, que convida â invenção de cada prática, em cada momento, em cada situação educativa.

Apenas como um exemplo, o Encontro Internacional Boca do Céu de contadores de histórias, sobre o qual discorri em outro artigo (MACHADO, 2010, p. 64-79), foi criado a partir de uma determinada compreensão da estrutura da Abordagem Triangular. A pergunta - de quantos modos é possível aprender sobre a Arte de contar histórias? - estruturou uma proposta arte educativa que dispõe três eixos de ações a configurar todas as edições do Encontro, desde 2001. As oficinas produção "com a mão na massa" de ações narrativas pelos participantes, as apresentações de diversos tipos de narradores propiciando as leituras/ escuta/ apreciação de arte narrativa em ação e as palestras, trocas e relatos de experiências como situações de reflexão a contextualizar as mais variadas questões narrativas. 
O "como fazer" esse Encontro foi possível a partir de uma certa leitura da Abordagem Triangular, entendida não como normativa, ou palavra de ordem ou modismo contemporâneo a ser seguido (ou contestado). E sim percebida na sua particularidade mais fundamental, instigante, jamais prescritiva. Durante uma semana a composição inter relacionada de atividades dentro dos três eixos propostos pode oferecer experiências que se sintetizam no centro de cada triângulo, ou seja, na percepção de cada participante do Encontro.

O eixo LEITURA passou na minha investigação a ser nomeado de Leituras designando não apenas a leitura da obra de arte, mas infinitos exercícios perceptivos de variadas formas de realidade.

Nenhuma novidade para Ana Mae, que ainda na época de pleno reinado do Modernismo, já propunha exercícios de percepção aos alunos da Escolinha de Arte de São Paulo, no início da década de 70. Disso me lembro muito bem.

Então a germinação da Abordagem Triangular já estava lá, na ação educativa de Ana Mae, desde sempre, em seus constantes questionamentos e experimentações, a fazer perguntas na direção do porvir.

Quando comecei a multiplicar os triângulos que podem estar contidos dentro da Abordagem Triangular foi como enveredar por uma trilha de liberdade, com um sentimento de alegria a me guiar: "Seja lá o que for que as pessoas disserem para você, a vida diz respeito à alegria e se você perder isso, então..." (SHAH, 2016, p. 9).

Percebi essa ação não como mero exercício intelectual, mas como algo útil no aprofundamento de minha compreensão dos inúmeros níveis e articulações da prática docente. Antes de mais nada como uma espécie de libertação do enfadonho pensamento linear - em que "isto mais isto é igual àquilo" - que sufoca os planejamentos: o que me deixa livre, a mim e aos alunos, para fazer perguntas e tecer relações ao sabor de cada particular processo de conhecer. Processo que não é livre no sentido de uma "livre expressão", como algo que viria de dentro, como se " dentro" fosse uma fonte mágica, inesgotável e autogeradora. 
Mas livre por ter feito, digamos, uma bicicleta, modelo $\mathrm{x}$, época $\mathrm{y}$, que compreendi ser constituída por elementos semelhantes ou diferentes de outras bicicletas de outros modelos e épocas. Essa bicicleta foi-me apresentada de tal modo que pude aprender o que é necessário fazer para colocá-la em movimento, ou parar. Conhecendo dados de "contexto e funcionamento" posso ter a liberdade de sair pedalando como quiser, mundo afora. Me perdoem a metáfora óbvia demais.

De qualquer modo, essa e muitas outras leituras dessa Abordagem têm sido feitas por arte educadores que, ao se meterem a investigá-la, tem descoberto particulares tesouros que transformam seu modo de trabalhar.

Relata Lucia Gouvêa Pimentel:

Em sua dissertação de mestrado em Artes, Ensino de Artes: entre a imagem e a ação, Sâmara Carbonari Santana demonstra como o trabalho com Artes Visuais a partir da Abordagem Triangular ganhou um novo significado para ela, enquanto professora, e para os alunos que participaram de um projeto de criação de vídeos.

Em dois projetos - Máquinas e VídeoArte - feitos com alunos de uma escola particular de Belo Horizonte, criou metodologias que contemplavam o que ali era feito tradicionalmente nas aulas de Arte e propôs novos direcionamentos para outros trabalhos.

A autora considera que, naquela escola, o ver e o fazer já eram contemplados, mas ficava uma lacuna no contextualizar. Ao propor os projetos levou em consideração o que já vinha sendo feito e acrescentou a contextualização de forma a que suas aulas fizessem significativa diferença no modo como os alunos consideram as aulas de Arte.

$[\ldots]$

O projeto Vídeo Arte teve como objetivo propor a produção de um vídeo em grupo, mas com o prévio contato com produções audiovisuais feitas por artistas e com o estudo da contextualização dos ambientes dos alunos (PIMENTEL, 2010, p. 213).

\section{O eixo da Produção}

A produção da Abordagem Triangular tem a marca do processo coerente e íntegro de uma vida em constante movimento de abertura incondicional para o conhecimento.

Luta política, embates ideológicos, encantamento na fruição da Arte, textos com formulações explosivas, falas candentes e defesas militantes a favor do digno estabelecimento da Arte Educação no Brasil, tudo isso se combina na constituição de 
uma trajetória na qual a Abordagem Triangular floresceu, entre muitas outras ações importantes.

Sua frutificação, no entanto, depende dos arte educadores brasileiros.

Certamente essa possibilidade não tem nada a ver com a ideia bastante difundida de "aplicar" a Abordagem, o que não faz o menor sentido. Muito menos tem a ver com certas críticas estéreis que visam reduzi-la por meio de visões inconsequentes, assimilando-a, por exemplo, à releitura de propostas estrangeiras.

"Os cães ladram e a caravana passa". Lembrei-me desse outro dito popular, não por acaso...

A ideia da caravana é eloquente aqui como referência a um movimento constante, perene, profundo, que atravessa os tempos da Humanidade desde que o mundo é mundo.

O mundo pode estar de cabeça para baixo, como esse em que vivemos hoje: às vezes quase duvido de que faz sentido continuar acreditando em valores humanos como a integridade e a beleza. Só que toda vez que irrompe na História uma invenção genuína do espírito humano, parece que nos conecta com possibilidades de transformação, com a força criadora que as anima. Uma epifania, como diria Gilbert Durand.

A luz do sol está, sempre esteve, brilhando no que chamamos às vezes de "alto do céu".

Cabe a cada folha tragá-la e traduzi-la em verde novo.

A Abordagem Triangular é uma dessas folhas que traga a História do Ensino da Arte e questões do passado e do presente, como parte de uma experiência de pesquisa e fruição artística que traduz em verde novo, como autêntica produção de conhecimento, uma possibilidade de luz. 
Que por sua vez poderá continuar a alumiar tantos outros trajetos de arte educadores brasileiros, desde que se disponham a procurar em si mesmos o caminho de produzir, apreciar e contextualizar seus conhecimentos de Arte.

Como fez Ana Mae durante toda sua vida. Com alegria.

São Paulo, 19 de fevereiro de 2017

\section{Referências}

MACHADO, Regina. Sobre mapas e bússolas: apontamentos a respeito da Abordagem Triangular. In: BARBOSA, Ana Mae Barbosa; CUNHA, Fernanda (Org.). Abordagem Triangular no ensino das Artes e Culturas Visuais. São Paulo: Cortez Editora, 2010. p 64-79.

PIMENTEL, Lucia Gouveia. Fruir, contextualizar e experimentar como possível estratégia básica e possibilidade de diversidade no ensino da Arte: o contemporâneo de vinte anos. In: BARBOSA, Ana Mae; CUNHA, Fernanda (Org.). Abordagem Triangular no ensino das Artes e Culturas Visuais. São Paulo: Cortez Editora, 2010. p. 211-228.

SHAH, Arif. The mines of light. Pick and Shovel, LLC, 2016. p. 9.

\section{Regina Machado}

Graduação em Ciências Sociais pela Universidade de São Paulo (1972), Mestrado em Educational Theater - New York University (1981) e Doutorado em Arte e Educação pela USP (1989). Atualmente é Professora Livre-docente aposentada pela Universidade de São Paulo. Professora aposentada de Graduação na área de Licenciatura no Departamento de Artes Plásticas/ECA/USP. Orienta junto a PósGraduação no Programa de Artes Visuais na área de concentração Teoria, Ensino e Aprendizagem da Arte no Departamento de Artes Plásticas da ECA/USP. Área de Conhecimento: Arte Educação, Contos tradicionais, Tradição Oral e Literatura Infantil.

E-mail: rtetelam@gmail.com

Currículo: http://lattes.cnpq.br/7054236023399474

Recebido em 19 de fevereiro de 2017 Aceito em 20 de maio de 2017 